\title{
Exclusion of the left atrial appendage with a novel device: Early results of a multicenter trial
}

\author{
Gorav Ailawadi, MD, ${ }^{a}$ Marc W. Gerdisch, MD, ${ }^{\mathrm{b}}$ Richard L. Harvey, MD, ${ }^{\mathrm{c}}$ Robert L. Hooker, MD, ${ }^{\mathrm{d}}$ \\ Ralph J. Damiano, Jr, MD, ${ }^{\mathrm{e}}$ Thomas Salamon, MD, ${ }^{\mathrm{f}}$ and Michael J. Mack, $\mathrm{MD}^{\mathrm{g}}$
}

\begin{abstract}
Objective: Up to $90 \%$ of embolic strokes that occur in patients with atrial fibrillation originate from the left atrial appendage. Exclusion of the left atrial appendage during cardiac surgery may decrease the future risk of stroke, especially in patients with atrial fibrillation or at high risk for developing atrial fibrillation. We report the initial results of a multicenter Food and Drug Administration trial to assess the safety and efficacy of a novel left atrial appendage exclusion clip.
\end{abstract}

\begin{abstract}
Methods: Patients undergoing elective cardiac surgery via median sternotomy with atrial fibrillation or a Congestive Heart Failure, Hypertension, Age $>75$ Years, Diabetes Mellitus, Stroke score greater than 2 were eligible for concomitant AtriClip (Atricure Inc, Westchester, Ohio) device insertion. Device insertion (35, 40,45 , and $50 \mathrm{~mm}$ ) was performed at any point after sternotomy on or off cardiopulmonary bypass. Safety was assessed at 30 days, and efficacy of left atrial appendage exclusion was assessed at operation (by transesophageal echocardiography) and 3-month follow-up (by computed tomography angiography or transesophageal echocardiography).
\end{abstract}

Results: A total of 71 patients (mean age, 73 years) undergoing open cardiac surgery at 7 US centers were enrolled in the study. The left atrial appendage in 1 patient was too small and did not meet eligibility criteria; the remaining 70 patients had successful placement of an AtriClip device. Intraprocedural successful left atrial appendage exclusion was confirmed in 67 of 70 patients (95.7\%). Although significant adverse events occurred in 34 of 70 patients $(48.6 \%)$, there were no adverse events related to the device and no perioperative mortality. At 3-month follow-up, 1 patient died and 65 of 70 patients $(92.9 \%)$ were available for assessment. Of the patients who underwent imaging, 60 of 61 patients $(98.4 \%)$ had successful left atrial appendage exclusion by computed tomography angiography or transesophageal echocardiography imaging.

Conclusions: In this small study, safe and atraumatic exclusion of the left atrial appendage can be performed during open cardiac surgery with the AtriClip device with greater than $95 \%$ success and appears to be durable in the short term by imaging. Long-term studies are needed to evaluate the efficacy in the prevention of stroke. (J Thorac Cardiovasc Surg 2011;142:1002-9)

Supplemental material is available online.

\footnotetext{
From the Department of Surgery, ${ }^{\mathrm{a}}$ University of Virginia, Charlottesville, Va; Department of Surgery, ${ }^{\mathrm{b}}$ St Francis Heart Center, Indianapolis, Ind; Department of Surgery, ${ }^{\mathrm{c}}$ Macon Cardiovascular, Macon, Ga; Department of Surgery, ${ }^{\mathrm{d}}$ Spectrum Health, Grand Rapids, Mich; Department of Surgery, ${ }^{\mathrm{e}}$ Washington University, St Louis, Mo; Department of Surgery, ${ }^{\mathrm{f}}$ Mount Carmel, Columbus, Ohio; and Department of Surgery, ${ }^{\mathrm{g}}$ Baylor Heart Hospital, Plano, Tex.

Funding provided by Atricure Inc, West Chester, Ohio. ClinicalTrials.gov number NCT00779857.

Disclosures: Authors have nothing to disclose with regard to commercial support.

Read at the 91st Annual Meeting of The American Association for Thoracic Surgery, Philadelphia, Pennsylvania, May 7-11, 2011.

Received for publication May 14, 2011; revisions received July 4, 2011; accepted for publication July 25, 2011; available ahead of print Sept 9, 2011.

Address for reprints: Michael J. Mack, MD, 1100 Allied Dr, Plano, TX 75093 (E-mail: michael.mack@baylorhealth.edu).

0022-5223/\$36.00

Copyright $($ c 2011 by The American Association for Thoracic Surgery doi:10.1016/j.jtcvs.2011.07.052
}

Atrial fibrillation (AF) is a well-known risk factor for stroke, increasing the lifetime risk for a patient by up to 5-fold. ${ }^{1}$ There is evidence that up to $90 \%$ of embolic strokes that occur in patients with AF originate from the left atrial appendage (LAA). ${ }^{2}$ In addition, the LAA is thought to be a driver for $\mathrm{AF}$ in a small group of patients with persistent $\mathrm{AF}^{3}$ It has been recommended that the LAA be excluded or excised in patients undergoing surgical treatment for AF or mitral valve surgery in an effort to decrease the future risk of thromboembolism. ${ }^{4}$

Currently available surgical methods to isolate blood flow to the LAA include (1) suture ligation, (2) excision and suture closure, and (3) stapling exclusion with or without excision. However, removal of the LAA is not inconsequential because these techniques are imperfect and sometimes traumatic to the appendage. Moreover, when using techniques that do not remove the LAA, studies have documented residual blood flow through the closure line into the appendage during follow-up in up to one third of patients. ${ }^{5,6}$ It has been suggested that patients with persistent 


$\begin{aligned} & \text { Abbreviations and Acronyms } \\ & \text { AF }= \text { atrial fibrillation } \\ & \mathrm{AE} \text { adverse event } \\ & \mathrm{AVR} \text { aortic valve replacement } \\ & \mathrm{CABG}= \text { coronary artery bypass grafting } \\ & \mathrm{CHADS}= \text { Congestive Heart Failure, } \\ & \text { Hypertension, Age }>75 \text { years } \\ & \text { Diabetes Mellitus, Stroke } \\ &= \text { computed tomography } \\ & \text { angiography } \\ & \mathrm{CTA} \quad \text { Exclusion of Left Atrial } \\ & \text { Appendage with AtriClip } \\ & \text { Exclusion Device in Patients } \\ & \text { Undergoing Concomitant Cardiac } \\ & \text { Surgery } \\ &= \text { Food and Drug Administration } \\ &= \text { left atrial appendage } \\ &= \text { transesophageal echocardiography }\end{aligned}$

flow into the LAA have a greater likelihood of left atrial thrombus. ${ }^{6}$ A number of catheter-based endocardial and minimally invasive epicardial methods recently have been developed to treat the LAA. Recent reports suggest minimally invasive and percutaneous LAA closure as a standalone treatment for $\mathrm{AF}^{7,8}$

The AtriClip device (Atricure, West Chester, Ohio) is placed epicardially at the base of the appendage in an effort to exclude blood flow into the LAA. The Exclusion of Left Atrial Appendage with AtriClip Exclusion Device in Patients Undergoing Concomitant Cardiac Surgery (EXCLUDE) clinical trial is a nonrandomized, prospective multicenter trial designed to assess the safety and efficacy of this novel clip.

\section{MATERIALS AND METHODS Patients}

This study reports the results of the EXCLUDE trial (ClinicalTrials.gov number, NCT00779857). All patients provided written informed consent. Adult patients undergoing elective primary cardiac operations via median sternotomy, including coronary artery bypass grafting (CABG), valve repair or replacement, surgical Maze procedures (ablative or cut-and-sew), or atrial septal defect repair, were evaluated. Patients with any of the following criteria were eligible for enrollment and concomitant AtriClip device insertion: AF, age greater than 65 years with hypertension, age more than 75 years, previous stroke, or a Congestive Heart Failure, Hypertension, Age $>75$ Years, Diabetes Mellitus, Stroke $\left(\mathrm{CHADS}_{2}\right)$ score greater than 2 points ( 1 point for each risk factor, including presence of congestive heart failure, hypertension, age $\geq 75$ years, diabetes mellitus, or previous stroke [2 points]). The $\mathrm{CHADS}_{2}$ score was designed to estimate the risk of stroke in patients with non-rheumatic $\mathrm{AF}$ and is used to determine which patients with $\mathrm{AF}$ should be maintained on warfarin. ${ }^{22}$ Pertinent exclusion criteria included previous cardiac surgery, need for emergency cardiac surgery, creatinine greater than $200 \mu \mathrm{mol} / \mathrm{L}$, and steroid treatment. Complete inclusion and exclusion criteria are shown in Table E1. In addition, patients with evidence of LAA thrombus by intraoperative transesophageal echocardiography (TEE) were excluded. A total of 71 patients were enrolled at 7 centers in the United States (Figure 1). The first patient was enrolled in October 2008, and the last patient was enrolled in June 2009. The last 12-month follow-up visit was in June 2010.

\section{Device Placement}

The AtriClip device is a clip made of 2 parallel rigid titanium tubes with elastic nitinol springs covered with a knit-braided polyester sheath. ${ }^{11}$ At the time of this study, a large first-generation deployment tool was used, which has currently been replaced with a smaller applicator. Before sternotomy, the LAA was assessed by intraoperative echocardiography to ensure no evidence of intraatrial thrombus. After sternotomy, device insertion was performed at any point during the operation before, during, or without cardiopulmonary bypass and was based on surgeon preference. The base of the LAA was measured. Four different size clips were available (35, 40, 45, and $50 \mathrm{~mm}$ ) based on the size of the LAA base as previously described. ${ }^{9-11}$ The heart is rotated to the right such that the LAA is brought into view. The clip is placed at the base of the appendage avoiding the circumflex and pulmonary arteries. If the location of the clip is not satisfactory, the clip can be repositioned before deployment. Once the clip is in optimal position, it is closed and released from the deployment tool manually. Repositioning once deployed is challenging and requires careful manual opening of the clip and reinsertion on the deployment tool. Successful LAA exclusion was assessed intraoperatively by TEE.

\section{Safety and Efficacy End Points}

The primary safety end point was device-related adverse events (AEs) at 30 days. The primary efficacy end point of successful LAA exclusion was a composite of intraprocedural TEE exclusion of flow to the LAA and exclusion assessed at 3-month follow-up by computed tomography angiography (CTA). Patients who could not receive intravenous contrast for CTA because of allergy or poor renal function underwent assessment by TEE. Efficacy of appendage exclusion was adjudicated by an independent core laboratory.

Secondary end points included (1) device placement success defined by the ability to successfully implant the device to the target location, (2) technical success defined by the ability to successfully implant an AtriClip device in a patient, (3) intraprocedural success defined by successful exclusion of the LAA by visual assessment and TEE, and (4) 3-month successful exclusion of the LAA as assessed by core laboratory review of the CTA. Patients who were unable to undergo CTA because of renal insufficiency or contrast allergy were offered TEE at 3 months. These echocardiograms were assessed by individual sites. CTA and TEE have been reported in the literature as imaging modalities to assess the LAA. ${ }^{23,24}$ The target rate for the primary safety end point of device-related AEs was less than $10 \%$. The target rate for the primary efficacy end point of LAA exclusion was greater than $95 \%$.

\section{Statistical Analysis}

Data from this study were tabulated using descriptive statistics. Continuous variables are presented as means and standard deviations, as well as medians and ranges. For categoric variables, relative frequencies are provided.

Statistical evaluations of the primary outcome measures were performed using Bayesian analysis methods. Bayesian credible intervals were used to illustrate the certainty with which the $\mathrm{AE}$ rates and efficacy rates are estimated. This prospective study protocol used Bayesian analyses for the primary safety and efficacy analyses and was reviewed by the Food and Drug Administration (FDA) Center for Devices and Radiological Health before study initiation and in accordance with the Center for Devices and Radiological Health's "Guidance for the Use of Bayesian Statistics in Medical Device Clinical Trials." In the final analysis, the posterior distribution of LAA exclusion success rate and serious device-related $\mathrm{AE}$ rate are summarized graphically via histogram and with 1-sided $95 \%$ 


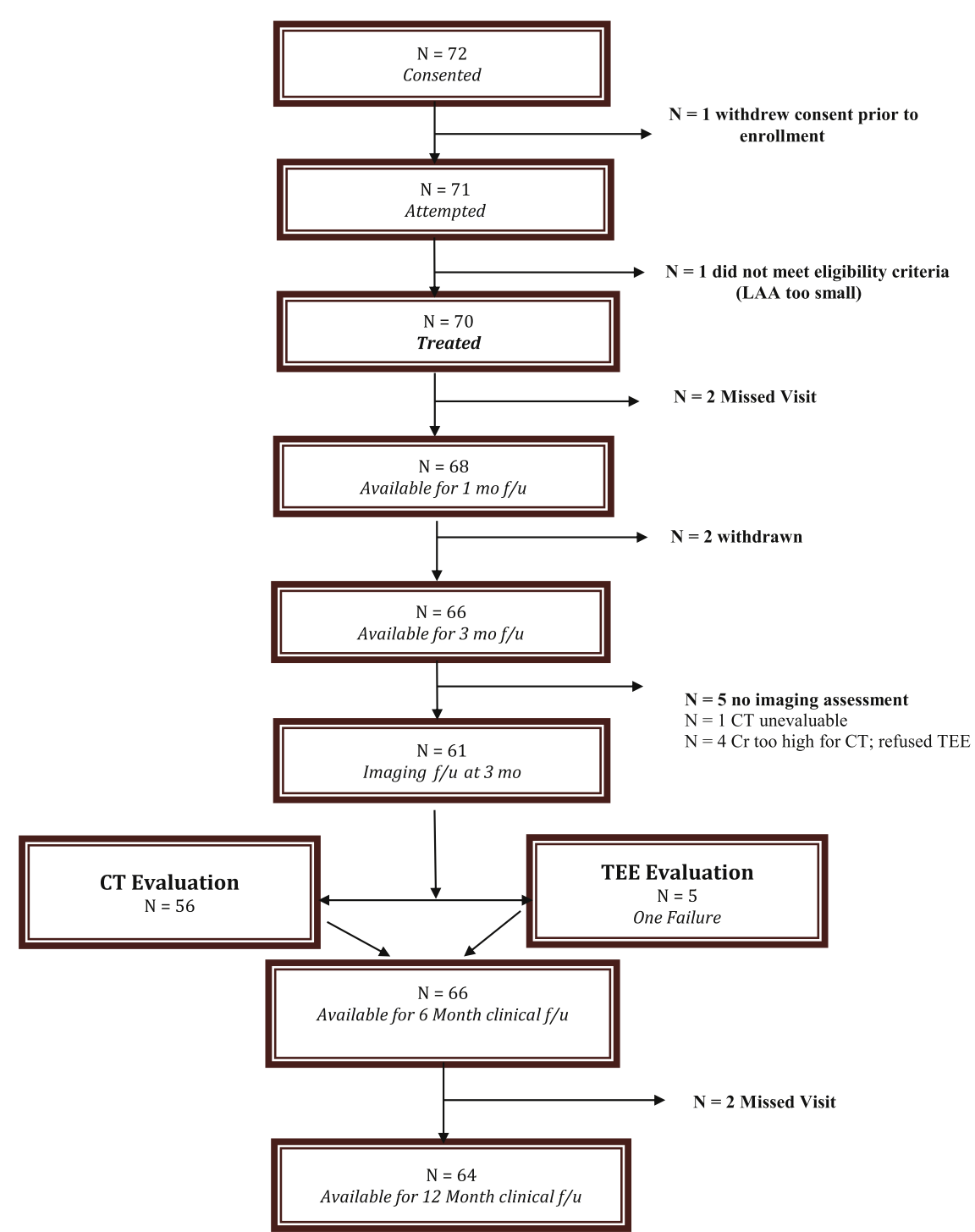

FIGURE 1. Enrollment and follow-up scheme of patients enrolled in the EXCLUDE trial. $f / u$, Follow-up; $C T$, computed tomography; TEE, transesophageal echocardiography.

Bayesian credible intervals. The Bayesian posterior probability of LAA exclusion success rate greater than $95 \%$ and Bayesian posterior probability of serious device-related $\mathrm{AE}$ rate less than $10 \%$ are reported.

AEs were summarized on the basis of seriousness, causality and association with the device, procedure, or comorbid condition. All AEs are summarized through 6 months according to the outcome of independent adjudication rather than as reported by the site.

Statistical analyses are produced using SAS Version 9.1 (SAS Institute Inc, Cary, NC). Statistical evaluations were performed using a 2-sided significance level of .05 unless otherwise specified.

\section{RESULTS}

\section{Patient Demographics and Baseline Information}

A total of 71 patients were enrolled in the EXCLUDE trial across 7 sites (1 patient withdrew consent; Figure 1). Enrollment ranged from 2 patients $(2.8 \%)$ at 1 site to 17 patients $(23.9 \%)$ at each of 2 sites. Median enrollment was 10 patients per site. The mean age for enrolled patients was 73.3 years, and $67.6 \%$ were male (Table 1 ). The majority of patients were white $(97.2 \%)$ and in functional New York Heart Association class II or III. The majority of patients underwent CABG (77.5\%), and approximately $40 \%$ underwent aortic valve replacement (AVR; Table 2). In addition, approximately $35 \%$ of enrolled patients underwent surgical Maze procedures. Twenty-six patients underwent an isolated procedure including isolated $\mathrm{CABG}$ ( $\mathrm{n}=17$ patients), AVR $(\mathrm{n}=6)$, or mitral valve operation $(\mathrm{n}=3)$. The remaining 45 patients had 2 or more procedures, most commonly CABG/AVR $(\mathrm{n}=14)$, CABG/ AVR/Maze $(n=5), C A B G / m i t r a l$ repair $(n=4)$. The remaining patients had some combination of mitral valve 
TABLE 1. Baseline and demographic variables of patients enrolled in the EXCLUDE study

\begin{tabular}{|c|c|}
\hline Patient variable & $\begin{array}{c}\text { Total } \\
\mathbf{N}=71\end{array}$ \\
\hline \multicolumn{2}{|l|}{ Baseline information } \\
\hline \multicolumn{2}{|l|}{ Age, y } \\
\hline Mean \pm SD & $73.3 \pm 8.2$ \\
\hline Median (range) & $74.0(48.0-87.0)$ \\
\hline \multicolumn{2}{|l|}{ Gender $[\%(\mathrm{n} / \mathrm{N})]$} \\
\hline Male & $67.6 \%(48 / 71)$ \\
\hline Female & $32.4 \%(23 / 71)$ \\
\hline \multicolumn{2}{|l|}{ Ethnic group $[\%(\mathrm{n} / \mathrm{N})]$} \\
\hline White & $97.2 \%(69 / 71)$ \\
\hline Black & $1.4 \%(1 / 71)$ \\
\hline Hispanic & $1.4 \%(1 / 71)$ \\
\hline \multicolumn{2}{|l|}{ NYHA classification $[\%(\mathrm{n} / \mathrm{N})]$} \\
\hline I & $12.7 \%(9 / 71)$ \\
\hline II & $45.1 \%(32 / 71)$ \\
\hline III & $40.8 \%(29 / 71)$ \\
\hline IV & $0.0 \%(0 / 71)$ \\
\hline Not done & $1.4 \%(1 / 71)$ \\
\hline \multicolumn{2}{|l|}{ Antiarrhythmic medication } \\
\hline Class I A & $0.0 \%(0 / 71)$ \\
\hline Class I B & $0.0 \%(0 / 71)$ \\
\hline Class I C & $4.2 \%(3 / 71)$ \\
\hline Class III & $5.6 \%(4 / 71)$ \\
\hline \multicolumn{2}{|l|}{ Cardiac and related medication } \\
\hline ACE inhibitors & $46.5 \%(33 / 71)$ \\
\hline Anticoagulants/antiplatelet & $78.9 \%(56 / 71)$ \\
\hline Beta-blockers & $52.1 \%(37 / 71)$ \\
\hline $\mathrm{Ca}+$ channel blockers & $22.5 \%(16 / 71)$ \\
\hline Diuretics & $63.4 \%(45 / 71)$ \\
\hline $\begin{array}{l}\text { Intraoperative TEE assessment } \\
\text { available }[\%(\mathrm{n} / \mathrm{N})][\%(\mathrm{n} / \mathrm{N})]\end{array}$ & $98.6 \%(70 / 71)$ \\
\hline \multicolumn{2}{|l|}{$\mathrm{EF}(\%)$} \\
\hline Mean $\pm \mathrm{SD}(\mathrm{N})$ & $52.3 \pm 12.7(69)$ \\
\hline Median (range) & $55.0(20.0-90.0)$ \\
\hline \multicolumn{2}{|l|}{ Left atrial size $(\mathrm{cm})$} \\
\hline Mean $\pm \mathrm{SD}(\mathrm{N})$ & $4.6 \pm 0.9(66)$ \\
\hline Median (range) & $4.6(1.9-6.5)$ \\
\hline Left atrial thrombus $[\%(\mathrm{n} / \mathrm{N})]$ & $0.0 \%(0 / 70)$ \\
\hline \multicolumn{2}{|l|}{ Criteria for inclusion } \\
\hline History of AF & $47.9 \%(34 / 71)$ \\
\hline CHADS score $>2$ & $38.0 \%(27 / 71)$ \\
\hline Age $>75$ y & $46.5 \%(33 / 71)$ \\
\hline Hypertension and age $>65 y$ & $77.5 \%(55 / 71)$ \\
\hline Previous stroke & $8.5 \%(6 / 71)$ \\
\hline
\end{tabular}

$S D$, Standard deviation; NYHA, New York Heart Association; $A C E$, angiotensinconverting enzyme; $T E E$, transesophageal echocardiography; $E F$, ejection fraction; $A F$, atrial fibrillation; CHADS, Congestive Heart Failure, Hypertension, Age $>75$ years, Diabetes Mellitus, Stroke.

operation (repair or replace), tricuspid repair, aortic procedure, and Maze procedure.

\section{Intraoperative Exclusion}

One patient's LAA was too small and did not meet eligibility criteria intraoperatively. The remaining 70 patients all
TABLE 2. Concomitant cardiac operations performed in the EXCLUDE study

\begin{tabular}{lc}
\hline \multicolumn{1}{c}{ Surgical procedure } & $\begin{array}{c}\text { Total } \%(\mathbf{n})(\mathbf{N}=\mathbf{7 1}) \\
\mathbf{N}=\mathbf{7 1} \%(\mathbf{n} / \mathbf{N})\end{array}$ \\
\hline CABG & $77.5 \%(55)$ \\
Mitral valve & $23.9 \%(17)$ \\
Repair & $16.9 \%(12)$ \\
Replacement & $7.0 \%(5)$ \\
Tricuspid valve & $5.6 \%(4)$ \\
Repair & $5.6 \%(4)$ \\
Aortic valve & $40.8 \%(29)$ \\
Replacement & $40.8 \%(29)$ \\
ASD/PFO closure & $0.0 \%(0)$ \\
Surgical (ablation or cut-and sew) Maze procedure & $35.2 \%(25)$ \\
\hline
\end{tabular}

$\overline{C A B G \text {, Coronary artery bypass grafting; } A S D \text {, atrial septal defect; } P F O \text {, patent fora- }}$ men ovale.

had LAA exclusion with the AtriClip device (Figure 1). There were no instances of damage to the appendage, circumflex artery, or pulmonary artery intraoperatively in any patient. Specifically, no patient had bleeding from the appendage and no additional repair sutures were required in any patient. Moreover, once deployed, the device did not migrate intraoperatively, nor was the clip or LAA removed in any patient. Intraoperatively, 67 of 70 patients $(95.7 \%)$ had successful exclusion of their appendage as assessed by postoperative TEE (Table 3). Despite successful visual exclusion of the LAA at the base (Figure 2, $A$ and $B$ ), a residual small stump of the appendage was apparent by TEE in these 3 patients.

\section{Follow-up}

Follow-up for all patients is shown in Figure 1. Two patients did not return for their 1-month visit. At 1-month follow-up, 68 patients were available for examination in the clinic. No patient had any clinical evidence of

TABLE 3. Efficacy results as determined by visual assessment and transesophageal echocardiography intraoperatively and by computed tomography angiography or transesophageal echocardiography imaging at 3 months

\begin{tabular}{lcc}
\hline & \multicolumn{1}{c}{$\begin{array}{c}\mathbf{9 5} \% \text { 1-sided } \\
\text { Eayesian credible } \\
\text { interval }\end{array}$} \\
\hline Procedural success & $\%(\mathbf{n} / \mathbf{N})$ & \\
by visual assessment & $95.7(67 / 70)$ & \\
by TEE & $97.1(68 / 70)$ & \\
3-mo success (CT or TEE) & $95.7(67 / 70)$ & \\
By method of assessment & $98.4(60 / 61)$ & $95-100$ \\
$\quad$ CT evaluation by core laboratory & $98.2(55 / 56)$ & \\
$\quad$ TEE evaluation by site & $100(5 / 5)$ & \\
Composite end point success & $95.1(58 / 61)$ & $90-100$ \\
(primary end point) & & \\
\hline TEE, Transesophageal echocardiography; $C T$, computed tomography.
\end{tabular}



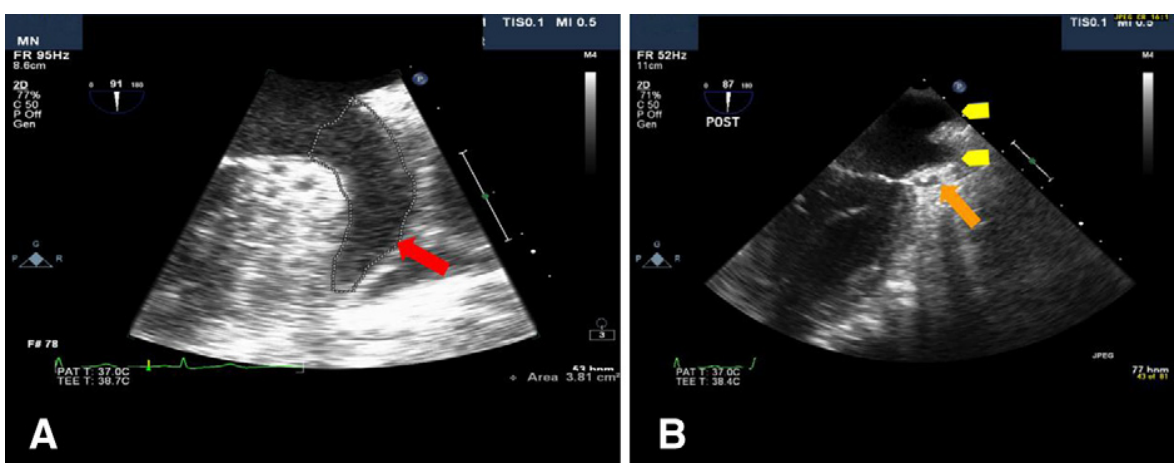

FIGURE 2. Intraoperative TEE demonstrating (A) patent LAA before AtriClip (Atricure Inc, Westchester, Ohio) device placement (red arrow) and (B) echocardiographic evidence of LAA exclusion after clip placement (orange arrow; yellow arrowheads indicate pulmonary veins).

complication from the AtriClip device. An additional 2 patients withdrew from the study after their 1-month visit and did not return for follow-up imaging. At 3 months, the remaining 66 patients were evaluated. A total of 57 of these remaining patients underwent CTA per the study protocol. In 1 of these patients, the CTA images were not obtained using the appropriate protocol and the patency of the LAA was unable to be evaluated. The remaining patients were not eligible for CTA because of elevated creatinine per individual site's protocol for administration of intravenous contrast agent. These 9 patients were all offered TEE, 4 of whom refused.

Thus, a total of 61 patients were evaluated with imaging at 3 months: CTA in 56 and TEE in 5. Of these 61 patients, all but $1(98.3 \%)$ showed evidence of complete exclusion of their LAA (Figure 3, $A$ and $B$ ). Of the 3 patients who did not have successful LAA exclusion by TEE at the time of procedure, only 1 remained unsuccessfully excluded at the 3-month imaging evaluation. The primary efficacy end point of composite intraprocedural exclusion by TEE and exclusion by CTA or TEE at 3 months was $95.1 \%$ (58/61) (Table 3).
A total of 66 patients and 64 patients were available at 6 and 12 months for clinical assessment, respectively. There were no AEs related to the clip (Table 4). The most common events included postoperative hemorrhage, pleural effusion, heart block, and congestive heart failure. No event was thought to be due to the AtriClip device or LAA closure. At 6-month follow-up, there were no strokes or cardioembolic events. However, at 12-month follow-up, 2 (3.1\%) of the available 64 patients had sustained a neurologic event. One patient had a transient ischemic attack with blurry vision that was attributed to a hypertensive crisis, and 1 patient had developed a clinical stroke of the anterior circulation that was attributed to cholesterol plaque. At 12-month follow-up, 19 patients $(29.7 \%)$ remained on chronic anticoagulation with warfarin.

\section{DISCUSSION}

Exclusion of the LAA has become the focus of a diverse number of novel devices. We report the results of the first epicardially placed device specifically designed to exclude blood flow into the LAA. In this FDA-Investigational
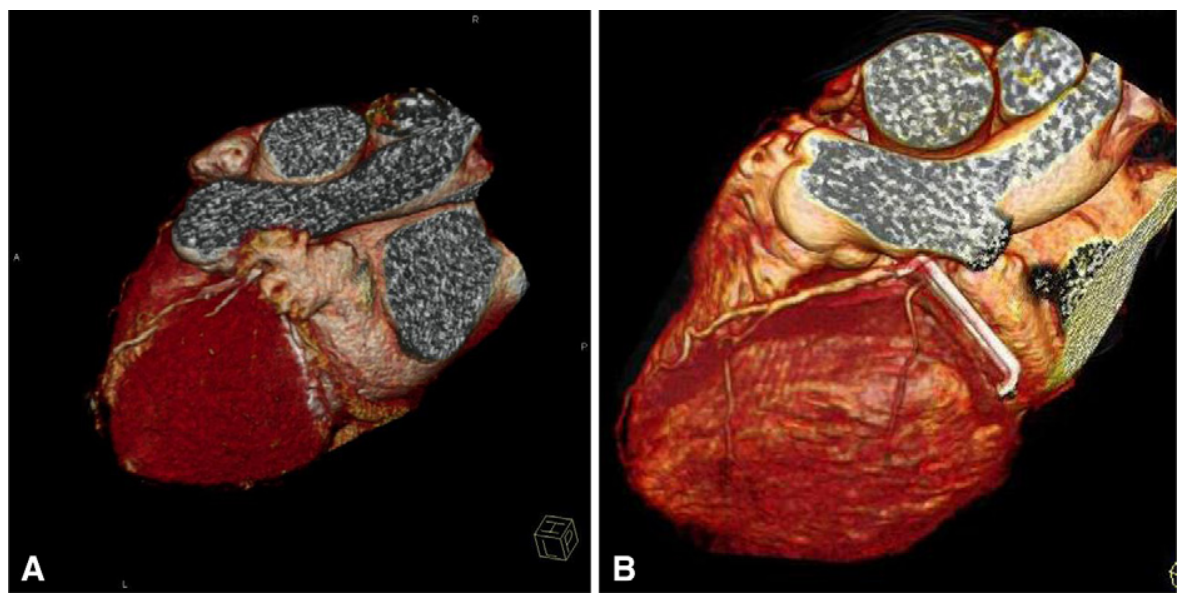

FIGURE 3. CT scan (A) preoperatively demonstrating patent LAA with contrast filling lumen and (B) postoperatively at 3 months after AtriClip device insertion demonstrating endovascular exclusion of the LAA. 
TABLE 4. Selected adjudicated adverse events after left atrial appendage exclusion with the AtriClip device (Atricure Inc, West Chester, Ohio)

\begin{tabular}{lcc}
\hline \multicolumn{1}{c}{ Adverse event name } & $\begin{array}{c}\% \text { (n/N) of patients } \\
\text { with event } \\
<\mathbf{3 0 ~ d}\end{array}$ & $\begin{array}{c}\% \text { (n/N) of patients } \\
\text { with event } \\
<\mathbf{6 ~ m o}\end{array}$ \\
\hline $\mathrm{AF}$ & $2.9(2 / 70)$ & $2.9(2 / 70)$ \\
Atrioventricular block & $10.0(7 / 70)$ & $10.0(7 / 70)$ \\
$\quad$ complete & & \\
Cardiac failure congestive & $4.3(3 / 70)$ & $5.7(4 / 70)$ \\
Gastrointestinal hemorrhage & $1.4(1 / 70)$ & $2.9(2 / 70)$ \\
Incision site infection & $1.4(1 / 70)$ & $1.4(1 / 70)$ \\
Pneumonia & $1.4(1 / 70)$ & $1.4(1 / 70)$ \\
Operative hemorrhage & $4.3(3 / 70)$ & $4.3(3 / 70)$ \\
Postprocedural hemorrhage & $5.7(4 / 70)$ & $5.7(4 / 70)$ \\
Ejection fraction decreased & $0.0(0 / 70)$ & $2.9(2 / 70)$ \\
Renal failure & $4.3(3 / 70)$ & $5.7(4 / 70)$ \\
Pleural effusion & $7.1(5 / 70)$ & $8.6(6 / 70)$ \\
Pulmonary embolism & $1.4(1 / 70)$ & $1.4(1 / 70)$ \\
Respiratory failure & $8.6(6 / 70)$ & $8.6(6 / 70)$ \\
Aortic dissection & $1.4(1 / 70)$ & $1.4(1 / 70)$ \\
Deep vein thrombosis & $1.4(1 / 70)$ & $1.4(1 / 70)$ \\
Hypotension & $2.9(2 / 70)$ & $2.9(2 / 70)$ \\
Device-related serious AE & $0.0(0 / 70)$ & $0.0(0 / 70)$ \\
Clip placement procedure- & $0.0(0 / 70)$ & $0.0(0 / 70)$ \\
$\quad$ related serious AE & & \\
\hline No events were attributable to LAA exclusion or the device. AF, Atrial fibrillation; \\
AE, adverse event. & &
\end{tabular}

Device Exemption study conducted at 7 sites across the United States, there were no significant AEs related to the device. Moreover, at 3-month imaging follow-up, 98.4\% of patients had complete exclusion of their LAA by CTA or TEE. It is important to note the 2 late neurologic events in these patients. Both of these were attributed by the source reports to hypertensive strokes, but a cardioembolic source cannot be ruled out entirely. On the basis of these findings, the AtriClip device demonstrates the safety and efficacy of LAA occlusion in the short-term and has been approved for use in patients to exclude the LAA during concomitant cardiac surgery. This is the first such device designed specifically for the LAA that is now available in the United States.

The most devastating complication from AF is stroke. It has been estimated that $20 \%$ to $30 \%$ of strokes are attributable to embolic events that develop as a consequence of AF. Moreover, current anticoagulation strategies carry a major risk of bleeding of $2.3 \%$ and intracranial hemorrhage risk of $0.9 \%$ yearly. ${ }^{12}$ Because an estimated $90 \%$ of thromboembolic events in patients with $\mathrm{AF}$ are thought to originate in the LAA, methods to exclude or remove the appendage might mitigate this risk without the dangers of anticoagulation.

Before recent novel approaches, surgical LAA exclusion involved suture ligation or staple excision. Both of these existing methods can result in incomplete exclusion in
$33 \%$ to $55 \%$ of cases. ${ }^{5,6}$ One retrospective study from the Cleveland Clinic of 137 patients reported successful LAA closure in $73 \%, 23 \%$, and $0 \%$ of patients who underwent surgical excision and closure, suture ligation, and staple exclusion, respectively. ${ }^{6}$ It has also been suggested that using a cutting stapler or cutting part of the remnant LAA off after staple removal may decrease the rate of patency or flow into the LAA. The Left Atrial Appendage Occlusion Study randomized patients undergoing CABG to LAA occlusion or control. Although the study was small, stapled exclusion resulted in $72 \%$ exclusion compared with $45 \%$ with suture ligation $(P=.14) .{ }^{13}$ Studies suggest that leaving a persistent communication with the LAA may have the highest rates of LAA thrombus and can result in the greatest risk of embolism. ${ }^{6,14,15}$ Specifically, $41 \%$ of patients with a patent LAA despite attempted surgical closure had documented thrombus in the LAA. ${ }^{6}$

Equally concerning to many surgeons is the danger in managing the frequently fragile LAA. In the Left Atrial Appendage Occlusion Study trial, $20 \%$ of patients who had their LAA excluded required additional suture repair for bleeding. ${ }^{13}$ Gillinov and colleagues ${ }^{16}$ reported using a buttressed cutting stapler in 222 patients and documented a $10 \%$ rate of bleeding below the suture line requiring additional suture repair. These results have led to trepidation by many surgeons to remove the LAA.

A number of other epicardial and endocardial devices are in various stages of development. The Embolic Protection in Patients With Atrial Fibrillation (PROTECT AF) randomized patients with $\mathrm{AF}$ and $\mathrm{CHADS}_{2} 1$ or more to closure using the Watchman device (Atritech, Inc, Plymouth, Minn) against warfarin. This device has not been approved because of the risk of complications, including pericardial effusion and periprocedural stroke, although it did demonstrate noninferiority compared with warfarin for risk of stroke, cardiovascular death, or other embolism. ${ }^{17}$ Another percutaneous placed device via a transseptal approach, the PLAATO (Appriva Medical Inc, Sunnyvale, Calif), has demonstrated good early results. ${ }^{18}$ Another percutaneous device, delivered via a subxiphoid epicardial approach, has been used successfully in a dog model. The LAA is identified on the basis of electrical activity, and a suture lasso is fluoroscopically placed around the LAA. ${ }^{7}$ Another device using a lasso and a percutaneous contrast-filled balloon to identify the LAA (Lariat device) has been documented in humans. ${ }^{19,20}$

Preclinical studies with the AtriClip device have documented complete LAA exclusion by magnetic resonance imaging and histologic evidence of endothelial formation on the occluded orifice of the LAA. ${ }^{9,10}$ Salzberg and colleagues ${ }^{11}$ reported the initial European study of 34 patients that documented no device-related perioperative complications and stable clip placement by CT imaging at 3 months. These results have led to European CE Mark 
approval. Thoracoscopic treatment of the LAA has been suggested as a sole therapy for patients with $\mathrm{AF}$ to minimize stroke risk. ${ }^{8}$ There is evidence to suggest that the AtriClip device results in electrical isolation, and the device has been used as an isolated therapy for focal atrial tachycardia. $^{21}$

Although the device studied is third generation, the deployment tool was a first-generation instrument. This reusable large deployment tool was cumbersome and can be used only via a sternotomy. There are 2 currently approved deployment tools. One is designed for open sternotomy, and the other is used for thoracoscopic approach. Both are smaller and more flexible, and have a lower profile than the deployment tool used in this report.

\section{Limitations}

This study is limited in the short-term imaging follow-up of only 3 months, although clinical follow-up extends to 12 months. This is a relatively small cohort of patients. Longer follow-up is needed to evaluate for evidence of device migration. This study was not designed to assess reduction in stroke risk. Late neurologic events developed in 2 patients, which did not appear to be related to the LAA to the best of our knowledge. A significantly larger randomized study would be required with longer-term follow-up to document any efficacy in stroke prophylaxis.

\section{CONCLUSIONS}

This multicenter initial trial suggests that exclusion of the LAA can be performed safely and without injury to the heart or surrounding structures during open cardiac surgery with the AtriClip device. In short-term follow-up, there is evidence of persistent LAA closure with no communication to the appendage. Long-term studies should be performed to evaluate the efficacy in the prevention of stroke and rule out the potential for device migration.

\section{References}

1. Wolf PA, Kannel WB, McGee DL, Meeks SL, Bharucha NE, McNamara PM. Duration of atrial fibrillation and imminence of stroke: the Framingham study. Stroke. 1983;14:664-7.

2. Blackshear JL, Odell JA. Appendage obliteration to reduce stroke in cardiac surgical patients with atrial fibrillation. Ann Thorac Surg. 1996;61:755-9.

3. Arantes L, Matsuo S, Lim KT, Knecht S, Jais P, Haissaguerre MJ. Left atrial appendage activity mimicking an epsilon wave on the surface electrocardiogram. Cardiovasc Electrophysiol. 2007;18:1114-5.

4. Calkins H, Brugada J, Packer DL, Cappato R, Chen SA, Crijns HJ, et al. HRS/ EHRA/ECAS expert consensus statement on catheter and surgical ablation of atrial fibrillation: recommendations for personnel, policy, procedures and follow-up. Europace. 2007;9:335-79.

5. Katz ES, Tsiamtsiouris T, Applebaum RM, Schwartzbard A, Tunick PA, Kronzon I. Surgical left atrial appendage ligation is frequently incomplete: a transesophageal echocardiographic study. J Am Coll Cardiol. 2000;36:468-71.

6. Kanderian AS, Gillinov AM, Pettersson GB, Blackstone E, Klein AL. Success of surgical left atrial appendage closure: assessment by transesophageal echocardiography. J Am Coll Cardiol. 2008;52:924-9.

7. Bruce CJ, Stanton CM, Asirvatham SJ, Danielsen AJ, Johnson SB, Packer DL, et al. Percutaneous epicardial left atrial appendage closure: intermediate-term results. J Cardiovasc Electrophysiol. 2011;22:64-70.
8. Blackshear JL, Johnson WD, Odell JA, Baker VS, Howard M, Pearce L, et al. Thoracoscopic extracardiac obliteration of the left atrial appendage for stroke risk reduction in atrial fibrillation. J Am Coll Cardiol. 2003;42:1249-52.

9. Fumoto H, Gillinov AM, Otaki Y, Akiyama M, Saeed D, Horai T, et al. A novel device for left atrial appendage exclusion: the third-generation atrial exclusion device. J Thorac Cardiovasc Surg. 2008;136:1019-27.

10. Salzberg SP, Gillinov AM, Anyanwu A, Castillo J, Filsoufi F, Adams DH. Surgical left atrial appendage occlusion: evaluation of a novel device with magnetic resonance imaging. Eur J Cardiothorac Surg. 2008;34:766-70.

11. Salzberg SP, Plass A, Emmert MY, Desbiolles L, Alkadhi H, Grünenfelder J, et al. Left atrial appendage clip occlusion: early clinical results. $J$ Thorac Cardiovasc Surg. 2010;139:1269-74.

12. Bleeding during antithrombotic therapy in patients with atrial fibrillation. The Stroke Prevention in Atrial Fibrillation Investigators. Arch Intern Med. 1996; 156:409-16.

13. Healey JS, Crystal E, Lamy A, Teoh K, Semelhago L, Hohnloser SH, et al. Left Atrial Appendage Occlusion Study (LAAOS): results of a randomized controlled pilot study of left atrial appendage occlusion during coronary bypass surgery in patients at risk for stroke. Am Heart J. 2005;150:288-93.

14. García-Fernández MA, Pérez-David E, Quiles J, Peralta J, García-Rojas I, Bermejo J, et al. Role of left atrial appendage obliteration in stroke reduction in patients with mitral valve prosthesis: a transesophageal echocardiographic study. J Am Coll Cardiol. 2003;42:1253-8.

15. Rosenzweig BP, Katz E, Kort S, Schloss M, Kronzon I. Thromboembolus from a ligated left atrial appendage. J Am Soc Echocardiogr. 2001;14:396-8.

16. Gillinov AM, Pettersson G, Cosgrove DM. Stapled excision of the left atrial appendage. J Thorac Cardiovasc Surg. 2005;129:679-80.

17. Holmes DR, Reddy VY, Turi ZG, Doshi SK, Sievert H, Buchbinder M, et al. Percutaneous closure of the left atrial appendage versus warfarin therapy for prevention of stroke in patients with atrial fibrillation: a randomised non-inferiority trial. Lancet. 2009;374:534-42.

18. Lynch M, Shanewise JS, Chang GL, Martin RP, Clements SD. Recanalization of the left atrial appendage demonstrated by transesophageal echocardiography. Ann Thorac Surg. 1997;63:1774-5.

19. Singh SM, Dukkipati SR, d'Avila A, Doshi SK, Reddy VY. Percutaneous left atrial appendage closure with an epicardial suture ligation approach: a prospective randomized pre-clinical feasibility study. Heart Rhythm. 2010;7:370-6.

20. Bartus K, Bednarek J, Myc J, Kapelak B, Sadowski J, Lelakowski J, et al. Feasibility of closed-chest ligation of the left atrial appendage in humans. Heart Rhythm. 2011;8:188-93.

21. Benussi S, Mazzone P, Maccabelli G, Vergara P, Grimaldi A, Pozzoli A, et al. Thoracoscopic appendage exclusion with an AtriClip device as a solo treatment for focal atrial tachycardia. Circulation. 2011;123:1575-8.

22. Gage BF, Waterman AD, Shannon W, Boechler M, Rich MW, Radford MJ. Validation of clinical classification schemes for predicting stroke: results from the National Registry of Atrial Fibrillation. JAMA. 2001;285:2864-70.

23. Jaber WA, White RD, Kuzmiack SA, Boyle JM, Natale A, Apperson-Hansen C, et al. Comparison of ability to identify left atrial thrombus by three dimensional tomography versus transesophageal echocardiography in patients with atrial fibrillation. Am J Cardiol. 2004;93:486-9.

24. Wazni OM, Tsao HM, Chen SA, Chuang HH, Saliba W, Natale A, et al. Cardiovascular imaging in the management of atrial fibrillation. J Am Coll Cardiol. 2006;48:2077-84.

\section{Discussion}

Dr Bryan Meyers (St Louis, Mo). There was a long list of inclusion and exclusion criteria. How restrictive was this trial and how representative is this patient population compared with the group of patients you encounter every day in your cardiac surgery practice?

Dr Ailawadi. On the basis of the exclusion criteria from this study, I would say approximately half of the patients I see in daily practice could have qualified for this. The most liberal of the inclusion criteria was age greater than 65 years and hypertension. So many of the patients we treat meet that criteria in this trial.

Dr Wiley Nifong (Greenville, $N C$ ). Great study, great results. We have been very happy using the clip clinically as well. I did 
notice early in the learning curve it looked like there were 3 misfires. Of course, while you are using it, you can get it down seated well. It appears, in the beating heart, to guide itself down. After it fires, I assume you could just use a wire cutter? You could remove it if you placed it and noticed it was not seated correctly, is that correct?

Dr Ailawadi. There are a couple of points to mention about deploying the device. The deployment device we used in this study was a large metal reusable tool, with a manual release. Once you release it, it is difficult, but it can be removed. You do not need a wire cutter, but you essentially take 2 pick-ups, separate the clip, and pull it off and then reattach it to the deployment tool and put it on again. The current FDA-approved device has a mechanism to open and close, and once you are happy with positioning, then you go ahead and cut the 4 sutures. So the current deployment device allows repositioning until it is in optimal position.

Dr Azhar Hossain (Indianapolis, Ind). How do you determine that you have been successful in excluding the entire appendage? As you know, there is residual appendage left, and the risk of thrombosis is still present. So are you using TEE assistance during the procedure?
Dr Ailawadi. It certainly can be done. I can tell you that during a sternotomy when you have the heart lifted up, it can be challenging to visualize by TEE. So in this situation, clip placement is by visual inspection. We do use TEE routinely in all of our cases. I have also performed this multiple times via a minimally invasive approach when performing a hybrid AF procedure or thoracoscopic AF procedure. In this situation, the heart is in its native position, and we can visualize by TEE before we deploy the clip.

Dr Bryan Meyers (St Louis, Mo). So you showed efficacy in the ability to exclude the appendage. The next step is going to be to show clinical effectiveness, and you are going to need a huge trial, aren't you, for the rare events you are trying to prevent?

Dr Ailawadi. Correct.

Dr Meyers. Any idea of where that is going next?

Dr Ailawadi. This is the million dollar question. I suspect it will require a large trial of at least 2000 patients. We will need to see what type of funding is available for this type of study. Ultimately, this will be required, not just with this particular device but with all the devices to see the clinical effectiveness of stroke reduction. 
TABLE E1. Inclusion and exclusion criteria for the EXCLUDE trial

Inclusion criteria

1. Subject is aged $\geq 18$ years

2. Subject has any 1 of the following risk factors and is thought to benefit from LAA exclusion

- CHADS score $>2$

- Age $>75$ y

- Hypertension and age $>65$ y

- History of AF (any classification)

- Previous stroke

3. Subject is scheduled to undergo elective non-endoscopic cardiac surgical procedure(s) including cardiac surgery for $\geq 1$ of the following: mitral valve repair or replacement, aortic valve repair or replacement, tricuspid valve repair or replacement, coronary artery bypass procedures, concomitant surgical (ablation or cut-and-sew) Maze procedure, patent foramen ovale closure, or atrial septal defect repair with the device deployed while on or prepared for cardiopulmonary bypass support

4. Subject is willing and able to provide written informed consent

5. Subject has a life expectancy of at least $2 \mathrm{y}$

6. Subject is willing and able to return for scheduled follow-up visits

Exclusion criteria

1. Previous cardiac surgery

2. Thrombus in the LAA/LA that cannot be evacuated before placement of the AtriClip device

3. Patients requiring surgery other than $\mathrm{CABG}$, cardiac valve surgery, surgical Maze procedure (ablation or cut-and-sew), PFO closure, or ASD repair

4. NYHA class IV heart failure symptoms

5. Need for emergency cardiac surgery (ie, cardiogenic shock)

6. Creatinine $>200 \mu \mathrm{mol} / \mathrm{L}$

7. LAA is not appropriate for exclusion based on intraoperative evaluations.

8. Current diagnosis of active systemic infection

9. Renal failure requiring dialysis or hepatic failure

10. A known drug or alcohol addiction

11. Mental impairment or other conditions that may not allow the subject to understand the nature, significance, and scope of the study

12. Pregnancy or desire to get pregnant within 12 mo of the study treatment

13. Preoperative need for intraaortic balloon pump or intravenous inotropes

14. Patients who have been treated with thoracic radiation

15. Patients in current chemotherapy

16. Patients on long-term treatment with oral or injected steroids (not including intermittent use of inhaled steroids for respiratory diseases) 17. Patients with known connective tissue disorders

LAA, Left atrial appendage; CHADS, Congestive Heart Failure, Hypertension, Age $>75$ Years, Diabetes Mellitus, Stroke; $A F$, atrial fibrillation; $L A$, left atrial; $C A B G$, coronary artery bypass grafting; $A S D$, atrial septal defect; $P F O$, patent foramen ovale; NYHA, New York Heart Association. 